NASA/TM-2002-211517

\title{
Application of DPIV to Enhanced Mixing Heated Nozzle Flows
}

Mark P. Wernet and James Bridges

Glenn Research Center, Cleveland, Ohio 
Since its founding, NASA has been dedicated to the advancement of aeronautics and space science. The NASA Scientific and Technical Information (STI) Program Office plays a key part in helping NASA maintain this important role.

The NASA STI Program Office is operated by Langley Research Center, the Lead Center for NASA's scientific and technical information. The NASA STI Program Office provides access to the NASA STI Database, the largest collection of aeronautical and space science STI in the world. The Program Office is also NASA's institutional mechanism for disseminating the results of its research and development activities. These results are published by NASA in the NASA STI Report Series, which includes the following report types:

- $\quad$ TECHNICAL PUBLICATION. Reports of completed research or a major significant phase of research that present the results of NASA programs and include extensive data or theoretical analysis. Includes compilations of significant scientific and technical data and information deemed to be of continuing reference value. NASA's counterpart of peerreviewed formal professional papers but has less stringent limitations on manuscript length and extent of graphic presentations.

- TECHNICAL MEMORANDUM. Scientific and technical findings that are preliminary or of specialized interest, e.g., quick release reports, working papers, and bibliographies that contain minimal annotation. Does not contain extensive analysis.

- CONTRACTOR REPORT. Scientific and technical findings by NASA-sponsored contractors and grantees.
- CONFERENCE PUBLICATION. Collected papers from scientific and technical conferences, symposia, seminars, or other meetings sponsored or cosponsored by NASA.

- SPECIAL PUBLICATION. Scientific, technical, or historical information from NASA programs, projects, and missions, often concerned with subjects having substantial public interest.

- TECHNICAL TRANSLATION. Englishlanguage translations of foreign scientific and technical material pertinent to NASA's mission.

Specialized services that complement the STI Program Office's diverse offerings include creating custom thesauri, building customized data bases, organizing and publishing research results ... even providing videos.

For more information about the NASA STI Program Office, see the following:

- Access the NASA STI Program Home Page at http://www.sti.nasa.gov

- E-mail your question via the Internet to help@sti.nasa.gov

- Fax your question to the NASA Access Help Desk at 301-621-0134

- Telephone the NASA Access Help Desk at 301-621-0390

- Write to:

NASA Access Help Desk

NASA Center for AeroSpace Information 7121 Standard Drive

Hanover, MD 21076 
NASA/TM-2002-211517

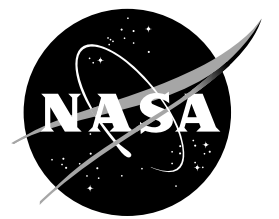

\section{Application of DPIV to Enhanced Mixing Heated Nozzle Flows}

Mark P. Wernet and James Bridges

Glenn Research Center, Cleveland, Ohio

Prepared for the

40th Aerospace Sciences Meeting and Exhibit

sponsored by the American Institute of Aeronautics and Astronautics

Reno, Nevada, January 14-17, 2002

National Aeronautics and

Space Administration

Glenn Research Center

May 2002 


\section{Acknowledgments}

We would like to thank Tom Griffin and Ray Loew for their support in the operation of the NATR facility. We would also like to thank Mr. W.T. John for his assistance in the setup and installation of the DPIV system.

Trade names or manufacturers' names are used in this report for identification only. This usage does not constitute an official endorsement, either expressed or implied, by the National Aeronautics and Space Administration.

Available from

NASA Center for Aerospace Information 7121 Standard Drive

Hanover, MD 21076
National Technical Information Service 5285 Port Royal Road Springfield, VA 22100 


\title{
APPLICATION OF DPIV TO ENHANCED MIXING HEATED NOZZLE FLOWS
}

\author{
Mark P. Wernet and James Bridges \\ National Aeronautics and Space Administration \\ Glenn Research Center \\ Cleveland, Ohio 44135
}

\begin{abstract}
Digital Particle Imaging Velocimetry (DPIV) is a planar velocity measurement technique that continues to be applied to new and challenging engineering research facilities while significantly reducing facility test time. DPIV was used in the GRC Nozzle Acoustic Test Rig (NATR) to characterize the high temperature $(560 \mathrm{C})$, high speed $(>500 \mathrm{~m} / \mathrm{s})$ flow field properties of mixing enhanced jet engine nozzles. The instantaneous velocity maps obtained using DPIV were used to determine mean velocity, rms velocity and two-point correlation statistics to verify the true turbulence characteristics of the flow. These measurements will ultimately be used to properly validate aeroacoustic model predictions by verifying CFD input to these models. These turbulence measurements have previously not been possible in hot supersonic jets. Mapping the nozzle velocity field using point based techniques requires over 60 hours of test time, compared to less than 45 minutes using DPIV, yielding a significant reduction in testing time.
\end{abstract}

A dual camera DPIV configuration was used to maximize the field of view and further minimize the testing time required to map the nozzle flow. The DPIV system field of view covered $127 \times 267 \mathrm{~mm}$. Data were acquired at 19 axial stations providing coverage of the flow from the nozzle exit to $2.37 \mathrm{~m}$ downstream. At each measurement station, 400 image frame pairs were acquired from each camera. The DPIV measurements of the mixing enhanced nozzle designs illustrate the changes in the flow field resulting in the reduced noise signature.

\subsection{Introduction}

NASA's Advanced Subsonic Technology (AST) program had as its goal the reduction of aircraft noise in the current and near-term fleet. Hence, it focused on technologies that were compatible with current engine configurations. One of these engine component configurations deemed amenable to jet noise reduction was the separate flow nozzle. It was believed that nozzle modifications that decreased the core flow velocity by enhancing mixing would cause overall noise reduction. Any mixing enhancing modifications would only acceptable if they resulted in minimal thrust loss.

In 1997, a series of nozzle concepts submitted by General Electric Aircraft Engines, Pratt\&Whitney, and Allison/Rolls Royce were tested at NASA GRC, Saiyed, 2000. Several of these nozzle concepts provided significant noise benefits with negligible thrust penalty, Saiyed, et al., 2000. During the 1997 Separate Flow Nozzle Test (SFNT), many types of measurements were made on the jet flows: far-field acoustics, total and static pressure and total temperature surveys of the plume, infrared imagery of the plume, acoustic source distribution estimation by phased arrays, and Schlieren images. Combined together, these measurements describe the mean flow field and acoustic fields for the jet flows, providing some understanding of how changes in the flow field caused beneficial changes in the acoustic sources.

As successful as the 1997 SFNT was, one key class of information was not acquired: turbulence statistics, which are the main information that aeroacoustic theory requires to relate flow to sound. Specifically, leading theories require two-point space-time correlations of the velocity field as input in order to accurately predict the acoustic output of jet flows. Although such measurements were attempted, researchers were ultimately unsuccessful in obtaining this information in 1997. So important were these measurements that a second series of tests were performed as a part of the Quiet Airframe Technology (QAT) program in 2000 using the original NATR test rig, and this time the efforts were successful. Turbulence measurements, including two-point space correlations were obtained using DPIV for the three most important nozzle configurations. 


\subsection{Facilities}

The AST Separate Flow Nozzle Tests were conducted at the AeroAcoustic Propulsion Laboratory (AAPL) at NASA Glenn Research Center in Cleveland, Ohio. The scaled exhaust nozzle models were mounted on a hydrogen fired jet engine exhaust simulator rig inside a freejet, providing appropriate hot flow conditions in simulated flight.

The AAPL facility is a $19.8 \mathrm{~m}$ radius, anechoic, geodesic-dome. The walls of the dome and approximately half of the floor area are treated with acoustic wedges made from fiberglass wool to render the facility anechoic above $220 \mathrm{~Hz}$. Flows from all rigs are directed out the $16.7 \mathrm{~m}$ wide by $10.7 \mathrm{~m}$ high doorway into an open field.

Within the confines of the dome is the Nozzle Acoustic Test Rig (NATR), a free-jet, forward-flight simulation test rig, as shown in figures 1 and 2 . The duct is acoustically lined (inside and outside) and extends from an annular air ejector system to a plenum and transition (bellmouth) section that is an ASME long-radius, low-bypass-ratio nozzle followed by a free-jet nozzle duct having an exit inner diameter of $1.35 \mathrm{~m}$ and a nozzle centerline $3 \mathrm{~m}$ above the concrete floor, Castner, 1994. This arrangement provides a freejet Mach number up to 0.3 at $136 \mathrm{~kg} / \mathrm{s}$. By careful design of acoustic lining and flow conditioning screens in the tunnel, the freestream turbulence is less than 1 percent and the overall sound pressure level with the freejet operating is $55 \mathrm{~dB}$. A $7.3 \mathrm{~m}$ high wall, constructed of aluminum box beam covered with plywood and fiberglass wedges, separates the anechoic test area containing the NATR from the acoustically untreated part of the dome.

The last $3.7 \mathrm{~m}$ of the NATR is a constant diameter, unlined, duct. Test nozzle models are installed on the aft end of the hydrogen-fired jet exit rig (JER) that is located in this duct. The JER is the structure through which hot airflow is delivered to the test article via connections to facility compressed air supplies. For this program, the JER was constructed in a tandemstrut arrangement consisting of the hydrogen fueled dual stream rig augmented by a dual flow 'pod' attached just aft of the combustor. Only the core stream of the dual stream rig was used to provide the simulated hot core flow while the fan flow came from a secondary strut into the dual flow pod. This rig setup and arrangement relative to the NATR are shown in Figure 2.

Supply air at $3.2 \mathrm{MPa}(450 \mathrm{psi})$ is preheated to roughly fan flow temperature $(60 \mathrm{C})$ by a natural gas fired heat exchanger outside the dome. The flow is split into core and fan flows, which are independently metered and throttled down by a control valve in $10 \mathrm{~cm}$ diameter flow lines. The core air is brought in through the main strut of the JER and into the plenum at the upstream end of the rig. The air is passed through a hydrogen injector plate where the combustion of the hydrogen increases its temperature to that of the core flow of an aircraft engine $(560 \mathrm{C})$. After passing over flow mixing devices to ensure the temperature uniformity, the flow is passed through two choke plates: reticulated foam metal and screens. The reticulated foam metal was removed after initial tests revealed that it was being clogged by the flow seeding material. DPIV data taken before and after the removal of the foam metal did not reveal any appreciable changes in the flow quality. The rig operating point is maintained by monitoring the flow conditions at the charging station, which is located just downstream of the leading edge of the centerbody section. The centerbody is held in the middle of the core stream by three thin airfoil struts. The centerbody section also holds the nozzle plug. When assembled and positioned, the separate-flow exhaust system fan nozzle exit plane was $0.61 \mathrm{~m}$ downstream of the freejet exit. The nozzle model centerline was elevated about $3 \mathrm{~m}$ above the facility floor.

\subsection{Seeding}

For DPIV, the flow motion being measured is marked by use of particles. These particles must be sufficiently small so they will have no slip relative to the fluid (so that their motion is the same as the fluid motion). In addition, all fluid must be laden with particles at a density high enough that sufficient particles (5-10) are found in an interrogation region of the DPIV image. This goal is more challenging when several independently seeded flow streams are mixing together in the measurement region. In these tests we are mixing three fluids: the core stream; the fan stream; and the ambient. It is also crucial that the seed be fully mixed and dispersed in the flow upstream of the measurement region in order to assure good quality DPIV images. Finally, the seed must not be affected by the high temperatures of the gas; this is especially true of the seed in the core stream at $560 \mathrm{C}$.

\subsection{Dry seeder design}

In these tests, the core and bypass streams were seeded with aluminum oxide $\left(\mathrm{Al}_{2} \mathrm{O}_{3}\right)$ powder using two identical, specially built fluidized bed seeders. The specific gravity of the alumina powder is 3.96 and the particle size distribution has a mean of $0.7 \mu \mathrm{m}$ and a standard deviation of $0.2 \mu \mathrm{m}$. The fluidized bed seeder system is comprised of two chambers, a fluidized-bed chamber and a swirl chamber. The fluidized bed 
chamber has a felt metal plate near its bottom which holds the seed material and allows air to flow through it, levitating the seed. Air is introduced into this chamber from the bottom. The seed is levitated and carried off with the air through a 1" port in the chamber side. This seeded air is brought into the swirl chamber below a pair of small tangential jets that set up a swirling flow in the chamber. This swirl causes larger particles, or more likely aggregates of particles, to be thrown to the side of the chamber where they will drop to the bottom of the chamber. The remaining small particles are carried up through a port in the top of the chamber and are piped into the main air supply pipes for the fan and core flows. The flow seed injection points are 50 and 100 diameters upstream from the nozzle exit plane for the core and fan flows, respectively.

The fluidized bed seeders provided relatively uniform seeding density most of the time. The seeders were not entirely steady, occasionally producing dense clouds of seed material. Changes in internal separations must have loosened deposits of seed within the piping and rig during these changes in flow. Monitoring the rate at which seed was used, it is estimated that the seeders provided roughly 0.5 liters/hour each, seeding the flow at a rate of 20 particles $/ \mathrm{mm}^{3}$. Given the light sheet thickness of $0.2 \mathrm{~mm}$, this produces on the order of 16 particles in a $2 \mathrm{~mm}$ by $2 \mathrm{~mm}$ interrogation region. The core and fan stream seeders were usually left on during the run once DPIV image acquisition had begun, even during traverse movement and image storage periods.

\subsection{Freejet fogger}

If ambient air around the jet is not seeded, the measured velocity statistics will be biased because the low speed ambient fluid, entrained by the seeded jet fluid, will not be recorded. Ideally, the jet fluid and ambient fluid will be seeded at equal density. Having a freejet flow surrounding the model jet is actually an aid in accomplishing this goal since the surrounding fluid can be seeded evenly by introducing the seed sufficiently far upstream so that it can be thoroughly mixed before the measurement region.

In the current test the freejet flow was seeded with oil droplets generated by a light oil fog generator manufactured by Corona Technologies, Ltd of Canada, specifically model Vicount 5000 . This seeder produces droplets in the $0.2-0.3 \mu \mathrm{m}$ diameter range while consuming 3.6 liters/hour of mineral oil. The seeder functions by forcing the oil through a heated nozzle along with nitrogen, evaporating the oil in the heated nozzle and condensing it into the small droplets that are essentially 'dry', leaving a minimal oil film on surfaces. The fogger was activated shortly before data acquisition was to commence, and was typically left on during the entire 45 minute run period.

It is important to note that although the droplets were $0.2-0.3$ micron in diameter, the images formed on the imaging plane of the camera were larger, due to the diffraction limited spot size of the recording camera lens. This is satisfactory, providing both the fluid marker functionality and particles with less mass. The small, low mass droplets yield high frequency response flow tracers. Based upon DPIV images and on estimates of delivery rates of the fogger and the freejet mass flow at $\mathrm{M}=0.28(136 \mathrm{~kg} / \mathrm{s})$, the particle density was estimated to be 200 particles $/ \mathrm{mm}^{3}$ in the measurement region near the nozzle exit. Given the light sheet thickness of $0.2 \mathrm{~mm}$, this produces on the order of 160 particles in a $2 \mathrm{~mm}$ by $2 \mathrm{~mm}$ interrogation region.

Figure 3 is a typical image taken from one of the DPIV cameras at the core nozzle exit illustrating seeding density. Note the relative uniformity of the seed in the core and fan streams; this was not always the case, but did not seem to adversely affect the data within the range of variation we observed. Also note the shear layer vortices, which are discernable between the fan and ambient seeding layers (regions seemingly devoid of seed particles).

\subsection{DPIV System}

The DPIV system was mounted on a large traverse system in the NATR facility. The large traverse frame offered convenient locations for mounting the DPIV cameras, computer and laser system. A schematic layout of the DPIV system on the traversing frame is shown in figure 4 . The traverse frame was mounted on a set of tracks and utilized a worm gear drive for straight, repeatable surveys along the jet axial direction. The DPIV system was traversed from the model exit plane to $2.37 \mathrm{~m}$ downstream.

The field of view and spatial resolution requirements demanded that a two camera DPIV system be implemented. A pair of $1000 \times 1000$ pixel cross correlation cameras were mounted on the traverse frame, in a stacked arrangement. The cameras were mounted $1.32 \mathrm{~m}$ from the jet rig centerline and equipped with $85 \mathrm{~mm}$ focal length lenses. The axial traverse was limited to $2.29 \mathrm{~m}$ of travel. Further, due to optical restrictions and image resolution issues, the widest field of view that could be accommodated was $139 \mathrm{~mm}$ square. By dividing up the axial traverse into $127 \mathrm{~mm}$ increments with $12 \mathrm{~mm}$ overlap between frames, the total plane of data could be acquired in 19 
segments. The resultant camera field of view was $127 \times 127 \mathrm{~mm}$, or $127 \times 267 \mathrm{~mm}$ for the combined stacked camera system.

The light sheet illumination was provided using a 400 $\mathrm{mJ} /$ pulse dual head $\mathrm{Nd}$ :YAG laser operating at 532 $\mathrm{nm}$. The laser repetition rate was $10 \mathrm{~Hz}$. The beam exiting the laser was expanded into a $200 \times 0.2 \mathrm{~mm}$ sheet at the model centerline. The laser head and power supply, light sheet optics and DPIV cameras were all mounted on the traverse frame, ensuring that the DPIV cameras were always focused on the light sheet plane.

The laser pulses were synchronized with the cameras and framegrabbers using TSI's Insight software and synchronizer. The synchronizer controlled the timing of the laser pulses relative to the image acquisitions from the DPIV cameras. An inter-frame time of 2.2 $\mu$ s was used to collect the image data. The relatively short inter-frame time was selected to ensure that the particles remained in the light sheet for both exposures, since the instantaneous out of plane velocity component was anticipated to be as large as $150 \mathrm{~m} / \mathrm{s}$ in a nominally $450 \mathrm{~m} / \mathrm{s}$ axial flow. At each measurement station, 400 image frame pairs from each camera were recorded and stored. Each survey included 19 measurement stations, yielding 30 Gbytes of data per survey. At the completion of the measurement campaign of all nozzles at all conditions and orientations, over 460 Gbytes of image data had been acquired.

The collected DPIV image data were processed using an in-house developed code called PIVPROC (Wernet, 1999). The correlation based processing allows subregion image shifting and multi-pass correlation to improve the spatial resolution of the resultant velocity vector maps. A preprocessing grid was constructed, registered to the nozzle lip from the first measurement station, so that the individual velocity vector grids could be computed on a global uniform grid that spanned the 19 axial measurement stations. The preprocessing grid was used to determine the starting location of the correlation processing in each image, so that a contiguous velocity vector map would be obtained at the completion of the data processing. Five velocity grid cells overlapped in the radial direction (between the top and bottom camera images) and 3 grid points in the axial direction (adjacent measurement stations). In the multi-pass correlation processing, a first pass subregion size of $64 \times 64$ pixels was used, with $50 \%$ overlap, followed by a second pass using $32 \times 32$ pixel subregions again with $50 \%$ overlap. The resulting spatial resolution of the velocity vector grid was $2.24 \mathrm{~mm}$.
The procedure for computing the statistics from the series of processed DPIV image velocity vector maps utilized several acceptance criteria to qualify vectors and identify outliers: signal to noise ratio for image correlation, hard velocity cutoff limits and an automated procedure for identifying and removing outliers. In all of the data presented from these tests, a relative data quality metric is the number of accepted velocity vectors at a given grid point relative to the total number of image frame pairs processed (400). Typically, this value was between 380 to 400 , or a data acceptance rate of $>95 \%$.

\subsection{Models \& flow conditions}

Three nozzles were measured in detail using DPIV. These were the baseline (3BB), alternating 12 count chevron $\left(3 \mathrm{~A}_{12} \mathrm{~B}\right)$, and 24 count alternating tabbed nozzle $\left(3 \mathrm{~T}_{24} \mathrm{~B}\right)$, figure 5 . These nozzles were chosen because they had the most dramatic (and beneficial!) acoustic and mean flow changes as measured during the 1997 SFNT. The SFNT series models were named by a convention comprised of a number followed by two letters. The number signified bypass ratio and whether the model had an internal or external plug. The two single-letter designations denoting the type of mixing enhancement device on the core and on the fan, the first letter referring to the core nozzle and the second to the fan nozzle. Subscripts on the letters gave the count of the tabs or chevrons on each nozzle. For this test all models were of the $3 \times x$ series, being of bypass ratio 5 and having an external plug.

The test plan for the DPIV measurements was to thoroughly measure as much of the jet plume as possible within the axial limitations of the traverse, assuming symmetry. For the baseline $3 \mathrm{BB}$ nozzle this required only one radial plane. Because $3 \mathrm{~A}_{12} \mathrm{~B}$ and $3 \mathrm{~T}_{24} \mathrm{~B}$ models had a $30^{\circ}$ symmetry, this entailed acquiring seven planes of data. By virtue of the adapter spool piece just upstream of the final core nozzle having 9 holes on its upstream flange and 8 on its downstream, a $5^{\circ}$ angular increment in nozzle orientation was possible. Hence the angular increments were accomplished by rotation of the model while the DPIV optical system was kept fixed in a vertical orientation. Data was acquired on the lower half of the jet with the field of view allowing data to be processed starting roughly $1.2 \mathrm{~cm}$ above the centerline. Each radial plane was acquired in a separate test run, typically on different test days. This decreased the quality of the match when the planes were assembled in post processing, especially since the rig is known to thermally grow in an inconsistent manner. 
An additional complication comes from the fact that the light sheet must be slightly moved off the plane of symmetry so that the flare light from the model does not damage the camera sensor. By moving the light sheet approximately $2 \mathrm{~mm}$ off the model centerline (away from the camera), the light reflected from the model is directed away from the camera; or put another way, the camera cannot see the place on the model where the light sheet makes impact. This slight modification should be kept in mind when comparing data close to the model. It should also be noted that the model has been known to move about by $1-2 \mathrm{~mm}$ over a period of several minutes due to thermal loading, making precise location of the sheet relative to the model rather difficult.

Due to limitations in the amount of image data that could be stored on the DPIV acquisition computer (roughly 60GB uncompressed), only two complete data planes could be acquired on a given day. This filled two of the three disk drives, leaving the third to store the compressed images that were sent over the local ethernet to other computers for processing. Due to these limitations, of the seven planes per nozzle desired, only three, the $0^{\circ}, 15^{\circ}$, and $30^{\circ}$ angles, were full length. The other four planes were only measured for half the axial length as it was determined that the angular variations were minimal downstream of that point. Thus it should have taken roughly two and onehalf test days to acquire the data for one nozzle.

\subsection{Models tested}

\subsubsection{BB-Axisymmetric baseline nozzle}

Model 3BB was the baseline nozzle, being axisymmetric on both core and fan nozzles. This model represented a generic separate flow nozzle such as are flying on medium twin engine commercial transports today. The plug angle is approximately $16^{\circ}$. The core cowl exit diameter is $13.1 \mathrm{~cm}$ (cold) and the core cowl external boattail angle is approximately $14^{\circ}$. Also, at cold conditions, the core cowl exit plane is $10.8 \mathrm{~cm}$ downstream of the fan nozzle exit plane.

\subsection{2 $3 A_{12} B$-Alternating 12-count chevron core nozzle with axisymmetric fan nozzle}

Model $3 \mathrm{~A}_{12} \mathrm{~B}$ substituted an alternating chevron trailing edge on the core nozzle for the axisymmetric one of 3BB. Chevrons can be thought of as being cut into the otherwise axisymmetric nozzle to have the baseline throat at the half height of the chevrons. Basic chevrons follow flow lines of baseline nozzle past the throat. The alternating chevron core nozzle can be thought of as starting from a flow-aligned chevron design with half of the chevrons being bent into the core stream approximately $4.5^{\circ}$ with a small additional cusp to the chevron. The other half of the chevrons are bent into the fan stream by roughly $8^{\circ}$. Penetrations were designed to extend 2 boundary layer heights into the flow. More details about the original design philosophy and acoustic performance are given in Janardan, et al., 2000., the report on the 1997 SFNT generated by GEAE, the designers of this nozzle. The result is a mean core flow with a six-sided star-shaped cross-section shortly downstream of the plug.

Although its thrust coefficient was reduced by roughly $0.5 \%$ by the addition of the chevrons, this nozzle produced roughly $3 \mathrm{~dB}$ suppression at the takeoff power condition. Because of the extreme change in both mean flow profile and far-field noise produced by the alternating chevron design, this model was chosen for detailed DPIV measurements.

\subsection{3 $3 T_{24} B-24$ count alternating tabbed core nozzle with axisymmetric fan nozzle}

Model $3 \mathrm{~T}_{24} \mathrm{~B}$ substituted an alternating tab trailing edge on the core nozzle for the axisymmetric one of 3BB. Two aspects of the tab design distinguish it from the chevron design. First, the tabs protrude into the flow from the nominal flow alignment starting with a hard break, not a gradual bend. The tabs make an angle of approximately $45^{\circ}$ with the flow, making a significant flow blockage. Second, in alternating the tab bending pattern, six of the tabs were bent inward, 6 were bend outward, and 12 were left aligned with the flow. This six-count pattern then again resulted in a mean core flow with a six-sided star-shaped crosssection shortly downstream of the plug.

Although its thrust coefficient was reduced by roughly $1.0 \%$ by the addition of the tabs, the $3 \mathrm{~T}_{24} \mathrm{~B}$ nozzle produced roughly $3 \mathrm{~dB}$ suppression at the takeoff power condition. However, it produced much greater mixing than the $3 \mathrm{~A}_{12} \mathrm{~B}$ model, suppressing low frequency more, but producing more high frequency noise in balance. Because of the extreme change in both mean flow profile and far-field noise produced by the alternating tab design, this model was also chosen for detailed DPIV measurements.

\subsubsection{Flow setting: $P C 21, M=0.28$}

For the DPIV test only one flow condition was used, that being the power code 21 as defined in the SFNT97 test plan, and shown in Table 1. This condition is a simulation of a take-off power setting of a contemporary subsonic medium to large commercial transport craft. The facility controllers were set to maintain $0.5 \%$ tolerance of all four parameters. The freejet was run at $\mathrm{M}=0.28$, again to simulate flight 
effects during takeoff. This value was maintained during the runs to within $1.5 \%$.

Table 1:

\begin{tabular}{lll}
\hline Stream & NPR & $\mathrm{T}_{\text {total }}$ \\
\hline Fan & 1.830 & $60 \mathrm{C}$ \\
Core & 1.680 & $560 \mathrm{C}$ \\
\hline
\end{tabular}

\subsection{Results and Discussion}

The DPIV velocity vector maps were used to compute $1^{\text {st }}$ and $2^{\text {nd }}$ order statistics of the jet flow field and also to compute 2-point spatial correlations and integral length scales. In this report we will only present the mean flow and turbulent kinetic energy properties in the $0^{\circ}$ plane of the nozzle.

The data shown in figure 6 show color contours of the mean axial velocity component, denoted as $\langle U\rangle$. The 3BB model exhibits an axisymmetric flow field with velocities above $450 \mathrm{~m} / \mathrm{s}$ that extends $2 \mathrm{~m}$ from the nozzle exit plane. In contrast, the two enhanced mixing nozzles produce flow fields where the mean velocity is below $400 \mathrm{~m} / \mathrm{s}$ within $1.5 \mathrm{~m}$ of the nozzle exit. While subtle differences exist between the two mixer nozzle flow fields, they are in general very similar. Both mixing enhanced nozzles produce a strong spread and a high speed "finger" in the $0^{\circ}$ plane. The increased mixing and subsequent reduction in high mean velocities is readily apparent.

Figure 7 shows the turbulent kinetic energy in the flow field as color contours for the three model configurations tested. The turbulent kinetic energy is defined here as $\frac{1}{2}\left(\sigma_{u}^{2}+\sigma_{v}^{2}+\sigma_{v}^{2}\right)$ where $\sigma_{u}$ and $\sigma_{v}$ are the standard deviations in the $u$ and $v$ velocity components, respectively. Note that $\sigma_{v}$ has been added twice to account for the missing $\sigma_{w}$, since these were only two-component velocity measurements, and we are invoking the assumption of axisymmetric turbulence, $\left(\sigma_{v}=\sigma_{w}\right)$. The reduced mean velocities observed beyond $1.5 \mathrm{~m}$ downstream of the nozzle exit in figure 6 are accompanied by a significant reduction in turbulent kinetic energy, thereby accounting for at least part of the reduced noise production in the nozzles with enhanced mixing. The regions of increased mixing near the nozzle exit actually have higher turbulent kinetic energy, yielding stronger noise sources than the baseline nozzle in this region. The changes in turbulent kinetic energy agree qualitatively with the noise measurements made earlier in the SFNT, with a reduction in low frequency noise corresponding to the reduction in downstream turbulence, and an increase in high frequency noise corresponding to the increase in turbulence near the nozzle.

\subsection{Conclusions}

DPIV has been successfully used to characterize the mean and turbulent flow field properties in heated, axisymmetric, nozzle flows with and without mixing enhancement devices applied. Use of two DPIV cameras in a stacked arrangement enabled full coverage of the nozzle flow by a single axial translation of the DPIV system on a large frame traverse system. Collection of 400 velocity vector maps at each measurement station provided an adequate sample size for computation of the flow statistics. Use of the DPIV technique resulted in a factor of 80 reduction in total test time over traditional point based measurement techniques. The mixing enhanced nozzle designs yielded lower mean velocity flow fields with different turbulent kinetic energy properties than the baseline nozzle. Downstream of the nozzle $(>2 \mathrm{~m})$ there is a reduction in the turbulent kinetic energy, which at least partially accounts for the reduced noise signature of the enhanced mixer designs.

\subsection{References}

Castner, R. S., 1994 "The Nozzle Acoustic Test Rig: An Acoustic and Aerodynamic Free-Jet Facility", NASA TM 106495.

Janardan, B.A., Hoff, G.E., Barter, J.W., Martens, S., Gliebe, P.R., Mengle, V., and Dalton, W.N., 2000 "AST Critical Propulsion and Noise Reduction Technologies for Future Commercial Subsonic Engines Separate-Flow Exhaust System Noise Reduction Concept Evaluation," NASA CR 2000210039 .

Saiyed, N., ed., 2000 "Separate Flow Nozzle Test Status Meeting”, NASA CP 2000-210524.

Saiyed, N., Mikkelsen, K.L., and Bridges, J., 2000 "Acoustics and Thrust of Separate-Flow Exhaust Nozzles With Mixing Devices for High-Bypass-Ratio Engines", NASA TM 2000-209948.

Wernet, M. P., 1999 "Fuzzy Logic Enhanced Digital PIV Processing Software", Proceedings of the $18^{\text {th }}$ International Congress on Instrumentation for Aerospace Simulation Facilities (ICIASF), Toulouse, France. 

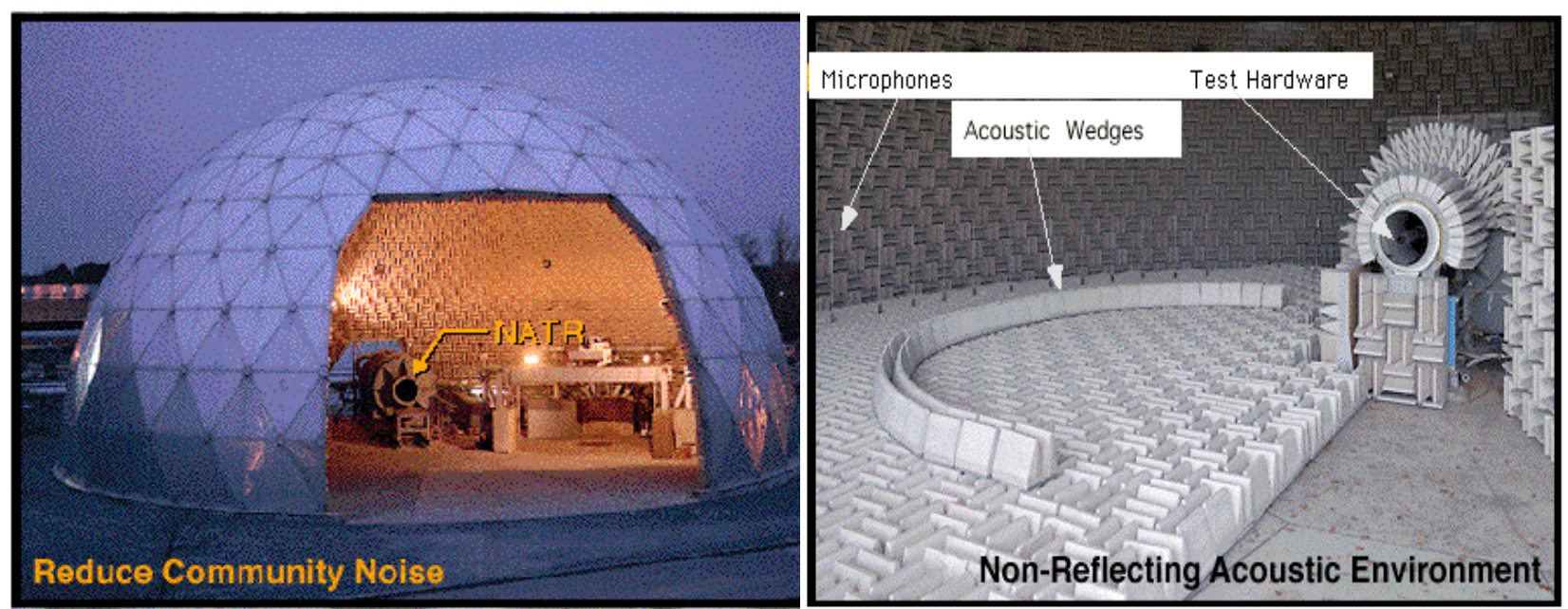

Figure 1: AeroAcoustic Propulsion Lab (AAPL) Dome facility shown on the left. The figure on the right shows the inside of the Dome facility and the Nozzle Acoustic Test Rig (NATR).

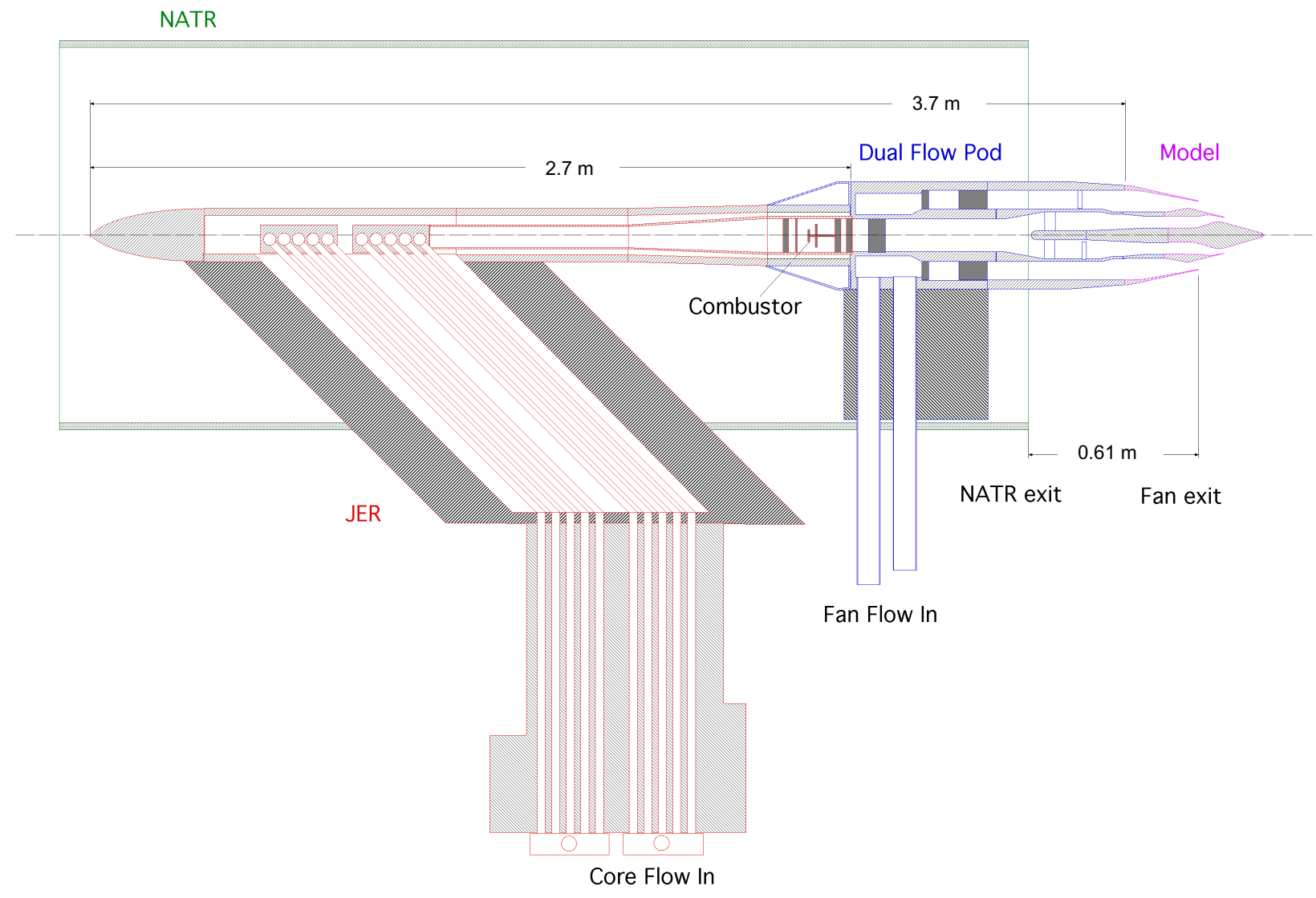

Figure 2: Jet Exit Rig (JER) with dual flow pod extension in the NATR. The mixing enhanced test models are mounted at the far right of the dual flow pod. 


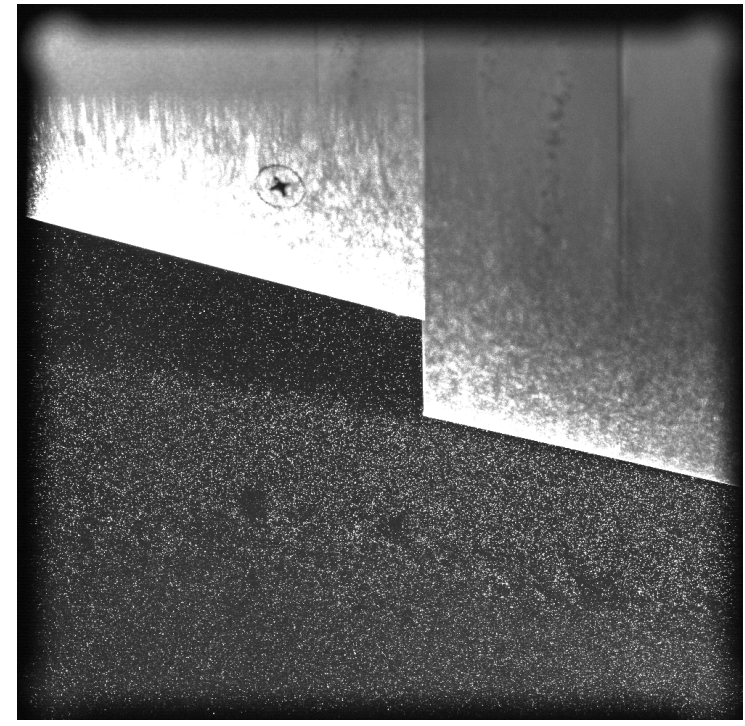

\section{Core Flow}

\section{Fan Flow}

Ambient

Figure 3: DPIV image illustrating seeding level in the core, fan and ambient regions.
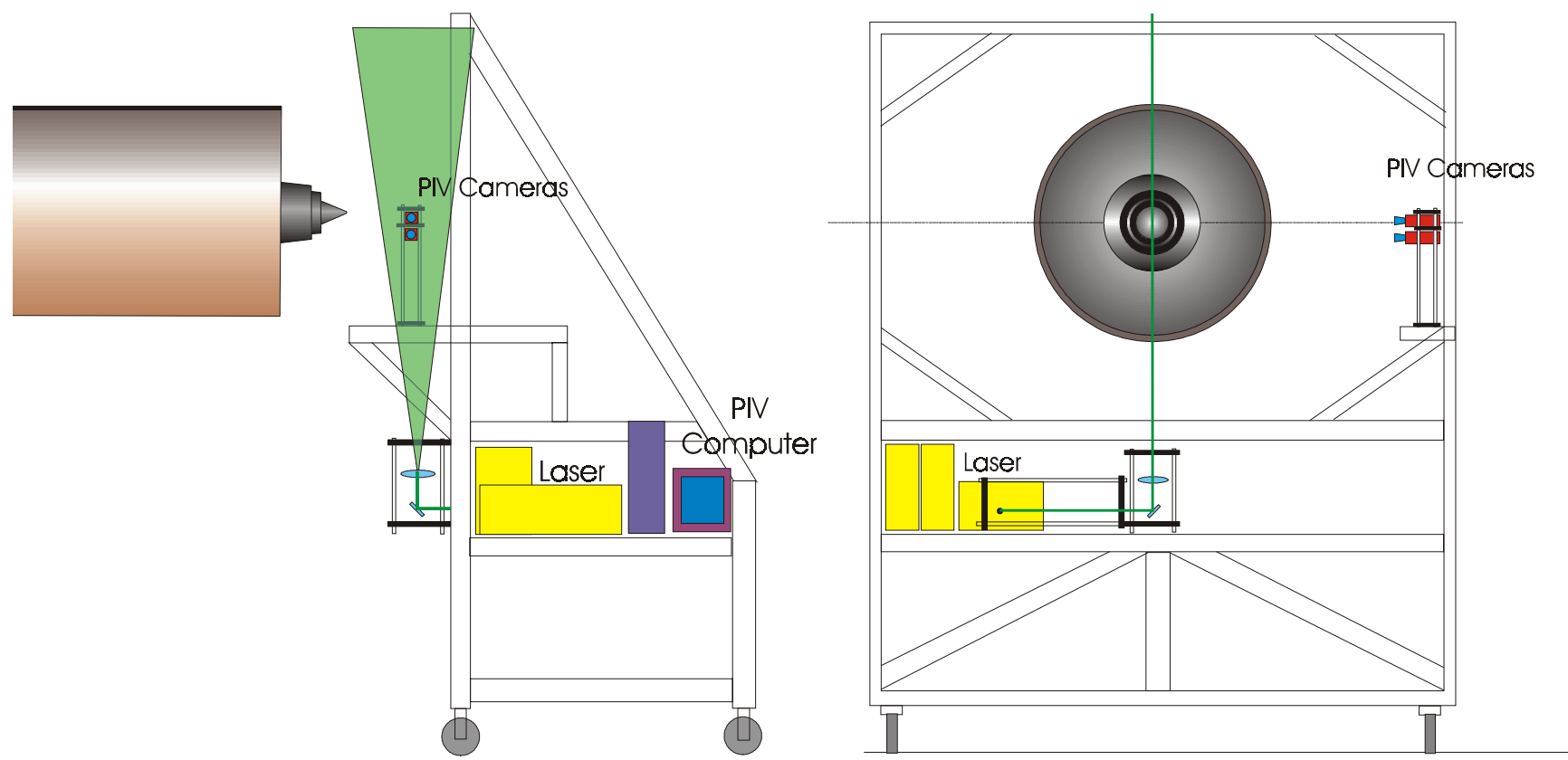

Figure 4: Side view and end view of the DPIV system mounted on the NATR traversing frame.
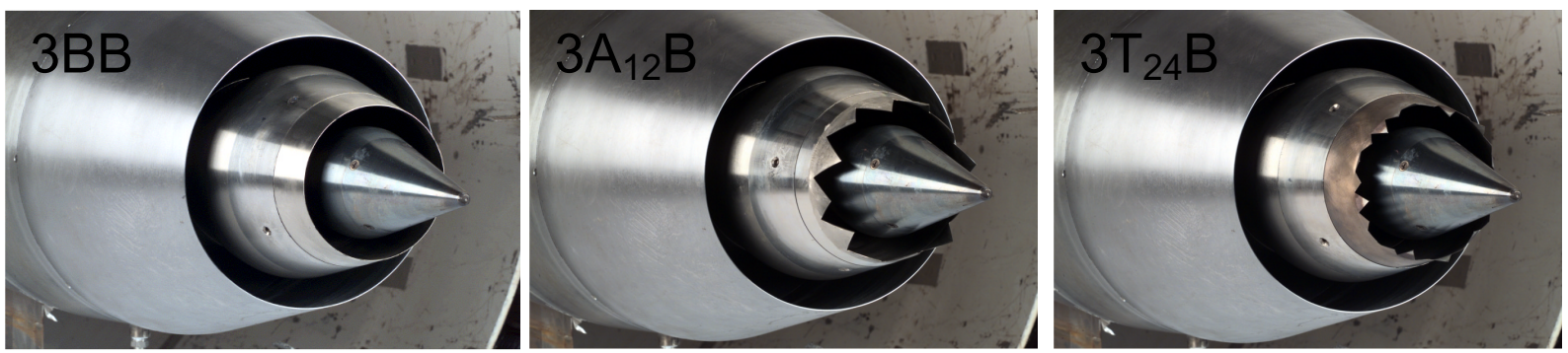

Figure 5: The three different nozzle designs tested: $3 \mathrm{BB}, 3 \mathrm{~A}_{12} \mathrm{~B}$, and $3 \mathrm{~T}_{24} \mathrm{~B}$. 


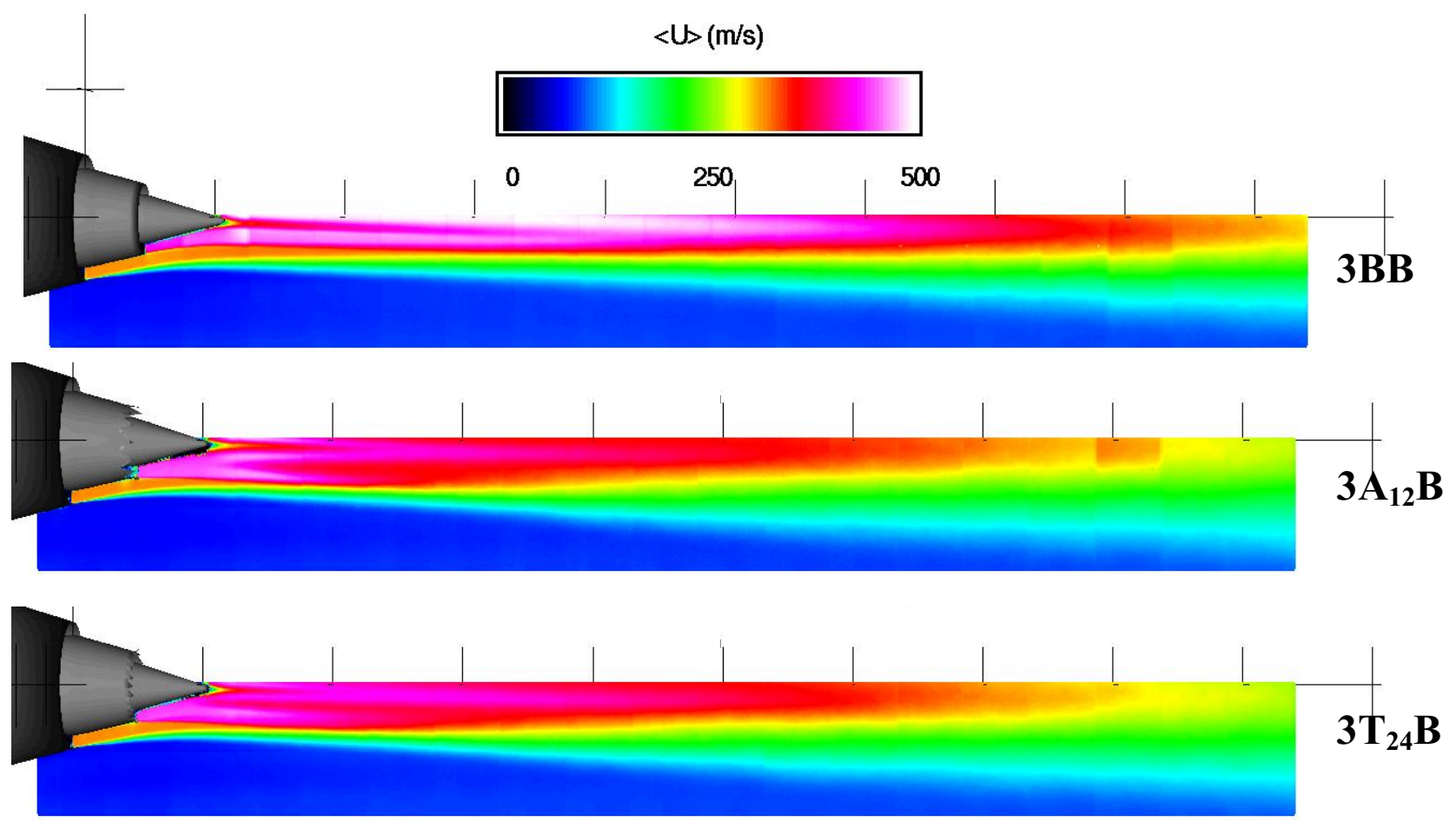

Figure 6: Mean axial velocity component (represented as color contours) for the three different nozzle designs tested. The enhanced mixing nozzles show a reduction in the mean velocity near the nozzle exit.

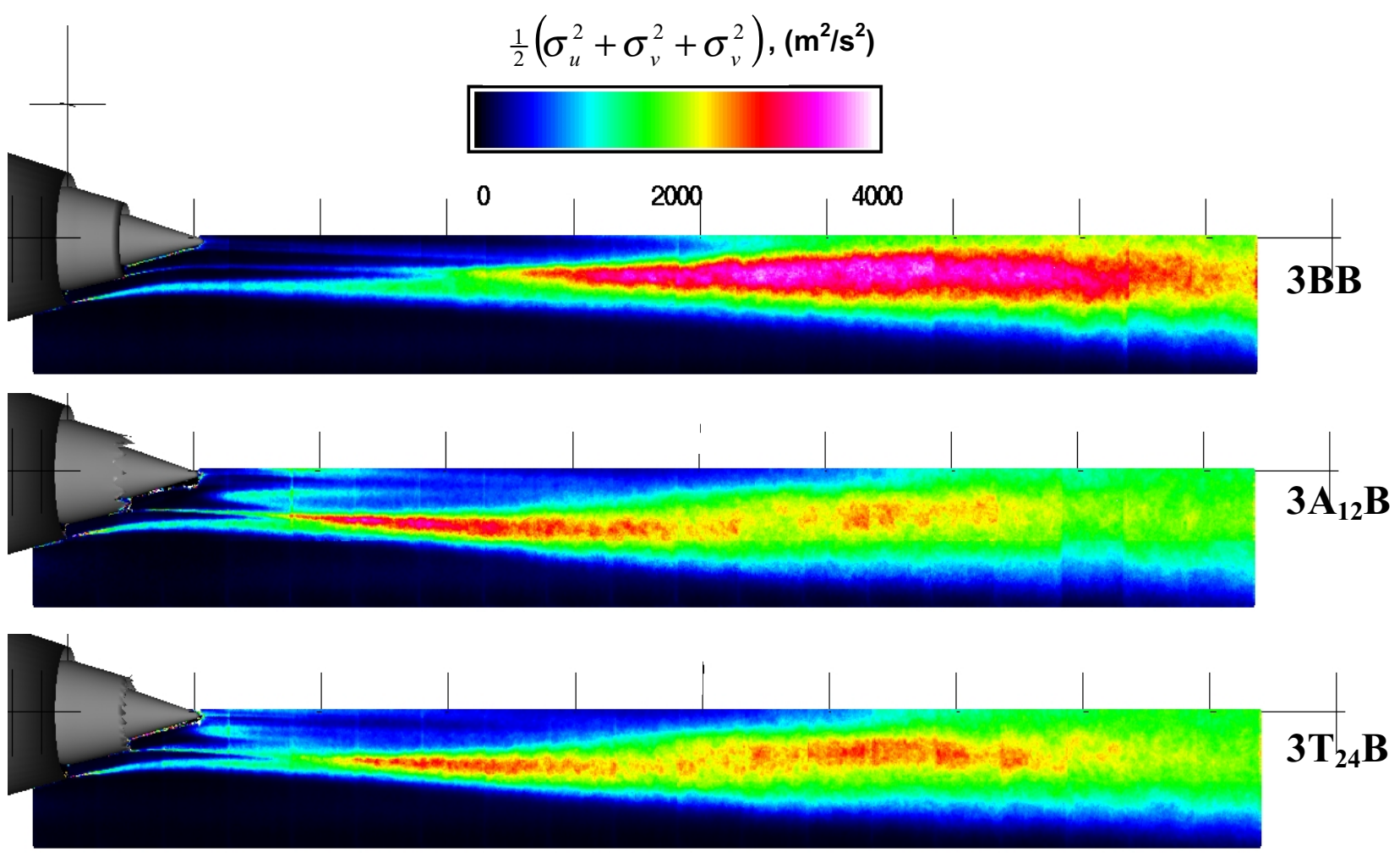

Figure 7: Total turbulence in the three models tested, again represented as color contours. The mixing enhanced nozzles have a higher total turbulence in the region of reduced mean velocity, and a lower total turbulence in the potential core. 
Public reporting burden for this collection of information is estimated to average 1 hour per response, including the time for reviewing instructions, searching existing data sources, gathering and maintaining the data needed, and completing and reviewing the collection of information. Send comments regarding this burden estimate or any other aspect of this collection of information, including suggestions for reducing this burden, to Washington Headquarters Services, Directorate for Information Operations and Reports, 1215 Jefferson Davis Highway, Suite 1204, Arlington, VA 22202-4302, and to the Office of Management and Budget, Paperwork Reduction Project (0704-0188), Washington, DC 20503.

\begin{tabular}{|l|l|l}
\hline 1. AGENCY USE ONLY (Leave blank) & $\begin{array}{c}\text { 2. REPORT DATE } \\
\text { May } 2002\end{array}$ & $\begin{array}{r}\text { 3. REPORT TYPE AND DATES COVERED } \\
\text { Technical Memorandum }\end{array}$ \\
\hline
\end{tabular}

4. TITLE AND SUBTITLE 5. FUNDING NUMBERS

Application of DPIV to Enhanced Mixing Heated Nozzle Flows

6. AUTHOR(S)

WU-781-30-12-00

Mark P. Wernet and James Bridges

7. PERFORMING ORGANIZATION NAME(S) AND ADDRESS(ES)

National Aeronautics and Space Administration

John H. Glenn Research Center at Lewis Field

Cleveland, Ohio 44135-3191

8. PERFORMING ORGANIZATION REPORT NUMBER

E-13311

9. SPONSORING/MONITORING AGENCY NAME(S) AND ADDRESS(ES)

National Aeronautics and Space Administration

Washington, DC 20546-0001

10. SPONSORING/MONITORING

AGENCY REPORT NUMBER

NASA TM-2002-211517

AIAA-2002-0691

\section{SUPPLEMENTARY NOTES}

Prepared for the 40th Aerospace Sciences Meeting and Exhibit sponsored by the American Institute of Aeronautics and Astronautics, Reno, Nevada, January 14-17, 2002. Responsible person, Mark P. Wernet, organization code 5520, 216-433-3752.

12a. DISTRIBUTION/AVAILABILITY STATEMENT 12b. DISTRIBUTION CODE

Unclassified - Unlimited

Subject Category: 35

Distribution: Nonstandard

Available electronically at http://gltrs.grc.nasa.gov/GLTRS

This publication is available from the NASA Center for AeroSpace Information, 301-621-0390.

13. ABSTRACT (Maximum 200 words)

Digital Particle Imaging Velocimetry (DPIV) is a planar velocity measurement technique that continues to be applied to new and challenging engineering research facilities while significantly reducing facility test time. DPIV was used in the GRC Nozzle Acoustic Test Rig (NATR) to characterize the high temperature $\left(560{ }^{\circ} \mathrm{C}\right)$, high speed $(>500 \mathrm{~m} / \mathrm{s})$ flow field properties of mixing enhanced jet engine nozzles. The instantaneous velocity maps obtained using DPIV were used to determine mean velocity, rms velocity and two-point correlation statistics to verify the true turbulence characteristics of the flow. These measurements will ultimately be used to properly validate aeroacoustic model predictions by verifying CFD input to these models. These turbulence measurements have previously not been possible in hot supersonic jets. Mapping the nozzle velocity field using point based techniques requires over 60 hours of test time, compared to less than 45 minutes using DPIV, yielding a significant reduction in testing time. A dual camera DPIV configuration was used to maximize the field of view and further minimize the testing time required to map the nozzle flow. The DPIV system field of view covered 127 by $267 \mathrm{~mm}$. Data were acquired at 19 axial stations providing coverage of the flow from the nozzle exit to $2.37 \mathrm{~m}$ downstream. At each measurement station, 400 image frame pairs were acquired from each camera. The DPIV measurements of the mixing enhanced nozzle designs illustrate the changes in the flow field resulting in the reduced noise signature.

14. SUBJECT TERMS

Jet noise; Particle velocimetry; Mixing
15. NUMBER OF PAGES

15

16. PRICE CODE

\begin{tabular}{|c|c|c|}
\hline $\begin{array}{c}\text { 17. SECURITY CLASSIFICATION } \\
\text { OF REPORT } \\
\text { Unclassified }\end{array}$ & $\begin{array}{c}\text { 18. SECURITY CLASSIFICATION } \\
\text { OF THIS PAGE } \\
\text { Unclassified }\end{array}$ & $\begin{array}{c}\text { 19. SECURITY CLASSIFICATION } \\
\text { OF ABSTRACT } \\
\text { Unclassified }\end{array}$ \\
\hline
\end{tabular}

NSN 7540-01-280-5500

Standard Form 298 (Rev. 2-89)

Prescribed by ANSI Std. Z39-18 298-102 